Jap. J. M. Sc. \& Biol., 15, 189-197, 1962

\title{
IMMUNOLOGICAL SIGNIFICANCE OF ANTISTREPTOLYSIN O (ASL) IN STREPTOCOCCAL INFECTIONS \\ II. A TWO-YEAR STUDY OF STREPTOCOCCAL INFECTIONS IN PRIMARY SCHOOL CHILDREN
}

\author{
MASATERU NOGUCHI, YuJIRO WAKAMATSU, RYuZO CHISUWA, \\ Shizuoka Prefectural Public Health Laboratory, Shizuoka \\ Hideo KUSAMA, MaKoto OHASHI, Hideo FUKUMI, \\ Department of Bacteriology I, National Institute of Health, Tokyo \\ ICHIRO TADOKORO, MASASHIRO KUDO, \\ Institute for Infectious Diseases, University of Tokyo, Tokyo \\ MORIMASA YOSHIOKA, TADAYOSHI KASUGA \\ Kitasato Institute for Infectious Diseases, Tokyo \\ AND TAKESHI HIRAYAMA \\ Department of Epidemiology, National Institute of Public Health, Tokyo
}

(Received: August 21st, 1962)

A study of streptococcal infections in primary school children had been conducted during a period of October, 1656 to September, 1958, under the sponsorship of the Ministry of Health and Welfare. The main purpose of this survey was to disclose the dynamics of streptococcal prevalence in school populations and to evaluate the relative importance of various factors which influence the host-parasite equilibrium.

During the study period, serum samples were obtained from some of the children studied, and were examined for the antistreptolysin O (ASL) content. Investigations were made as to whether the possession of ASL is related to the immunity to subsequent streptococcal reinfections, and a rise in ASL titer was used as a criterion for answering the question of whether streptococci harbored in the throat of children are inducing the reaction of the host or they are to be considered as simple saprophytic inhabitants.

The present report first describes a general outline of the epidemiological findings as the background of serological investigations, and then some immunological findings related to ASL are presented in order to contribute to the understanding of streptococcal infections in a group of children.

野口政輝・若松有次郎・千須和柳三（静岡県衛生研究所）

草間秀夫・大橋 誠・福見秀雄（国立予防衛生研究所細菌第一部）

田所一郎・工藤正四郎 (東京大学伝染病研究所)

吉岡守正・春日忠善（北里研究所）

平山 雄（国立公衆葦生院疫学部） 


\section{MATERIALS AND METHODS}

1. Bacteriological examinations: Between October, 1956 and September, 1958, some 250 children attending the first grade (at the beginning of the survey) of two primary schools in Shimizu, Shizuoka Prefecture, were selected for the study. They had throat swabs taken one to three times a month over two years. The swabs were cultured on agar plates containing $5 \%$ horse blood. Beta hemolytic streptococci isolated were grouped and typed by the technique previously described (Swift et al., 1943).

2. Serological examinations: Sera from some of the children were assayed for the ASL titer by the method previously reported by one of the authors (Kusama, 1958)

\section{RESULTS}

\section{Epidemiological Background}

\section{Seasonal Variations in the Occurrence of Group A Streptococcal Infections}

Seasonal variations in two rates related to the occurrence of Group A streptococcal infections during the study period are shown in Fig. 1. The solid line indicates the

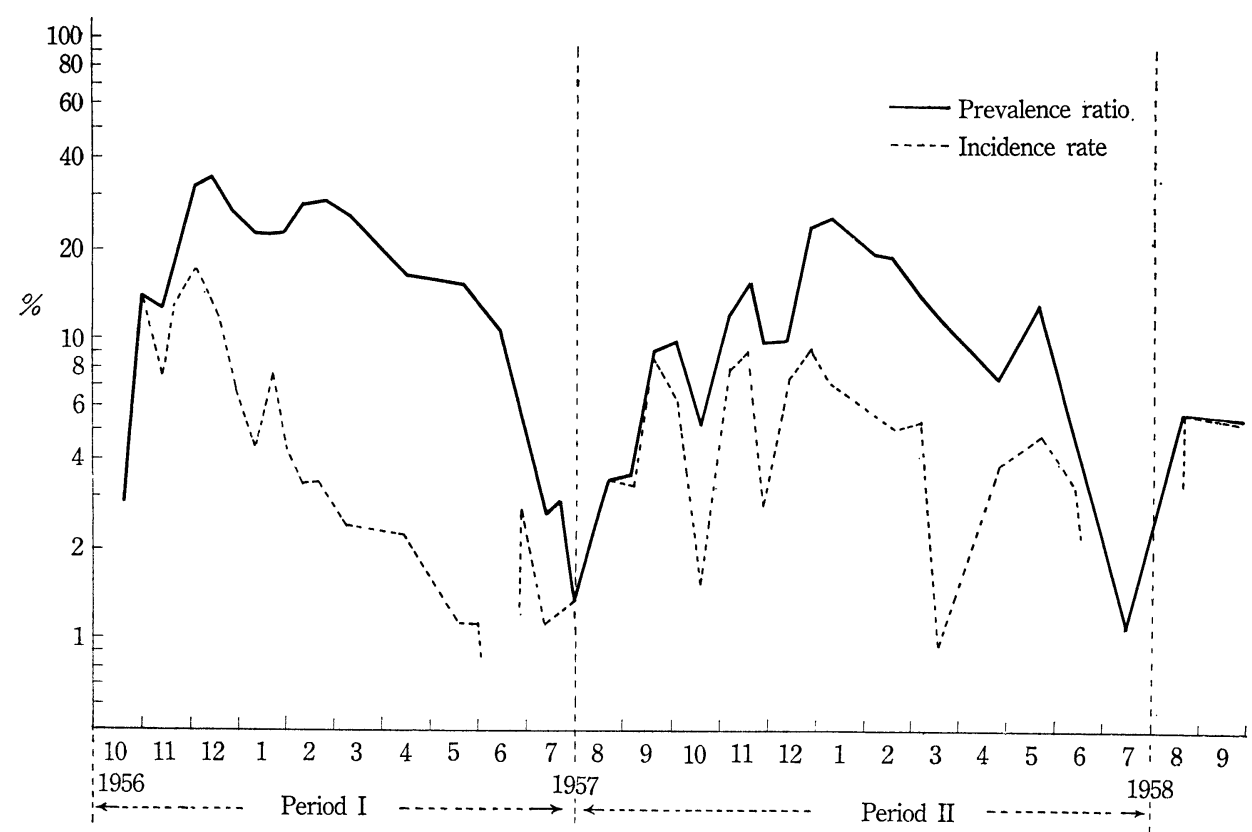

Fig. 1. Seasonal variation in the prevalence ratio and incidence rate of Group A streptococci.

prevalence ratio (the number of children harboring Group A streptococci divided by the total number or children examined at each time), which is a static presentation of a biologic equilibrium. Other than Group A, Groups $\mathrm{C}$ and $\mathrm{G}$ organisms were also isolated to less extents. Because of their minor importance in human infections, and because of a simpler presentation of the data, the descriptions related to Group $\mathrm{C}$ and $\mathrm{G}$ streptococci are omitted from the present report. The prevalence ratio began to 
increase early in the autumn of each year, reached the maximum at the end of year, gradually decreased in the spring of the next year, and then became lowest in summer. The wave of the ratio seems to be repeated in a similar fashion in each year. From this curve, it seems to be adequate to divide the whole study period into two, the period I (from October, 1956 to July, 1957) and period II (from August, 1957 to July, 1958).

The dotted line in the figure represents the incidence rate of Group A streptococcal infections (the number of children* from whom a Group A streptococcus was newly isolated at one time divided by the number of children from whom Group A organisms had not been isolated from the biginning of each period to the preceding survey time). The rate during each period was calculated independently, that is, infections during the period I were not taken into consideration in calculating the rate in the period II. The rate reached the maximum at the end of each calendar year and decreased thereafter, rather rapidly in the period I and more slowly in the period II.

Eighty-seven children out of $252(34.5 \%)$ and 98 out of $250(39.0 \%)$ continued to be free from Group A streptococcal infection during the periods I and II, respectively. Meanwhile, $18.0 \%$ (44 out of 245 ) had been negative for Group A streptococci throughout both periods.

\section{Seasonal Variations in the Occurrence of Prevalent Types of Group A Streptococci}

Among the Group A organisms isolated during the two-year period, types 3, 6 and 12 were most prevalent. Seasonal variations in the occurrence of each of these serologic type are shown in Fig. 2 by presenting the prevalence ratio and incidence rate as in Fig. 1. The incidence rate was derived by dividing the number of children from whom a type of Group A streptococcus was newly isolated at one time by those from whom the same type organisms had not been isolated from the beginning of each period to the preceding survey time, regardless of infections with other serologic types.

Types 3 and 12 were prevalent in the period I, and a few of these types appeared in the period II, whereas type 6 showed an entirely reverse situation, exhibiting a definite epidemic wave in the period II. It is evident that the incidence rate for each prevalent type reached the maximum in the early phase of epidemic wave. The types which constituted the epidemic wave were thus quite different in each period, although the wave of composite Group A organisms was rather similar in both periods.

\section{Duration of Infection with Each Prevalent Type of Group A Streptococcus}

Information as to how long the children harbor the same type of Group A streptococcus is an important guide in understanding the epidemiology of streptococcal infection. However, it was frequently encountered in the serial bacteriological examinations that the same serologic type had not been continuously isolated, but interrupted by the negative cultures from time to time. In such a case, an assumption was made that the child had been continuously infected with the same type of organisms, but variations due to the isolation techniques, the number and location of organisms in the throat, etc. prevented the continuation of positive isolation. The duration of infection

\footnotetext{
* If an infection with one type of Group A streptococcus was followed or accompanied by an
} infection with another type, the latter was also counted as a new infection. 


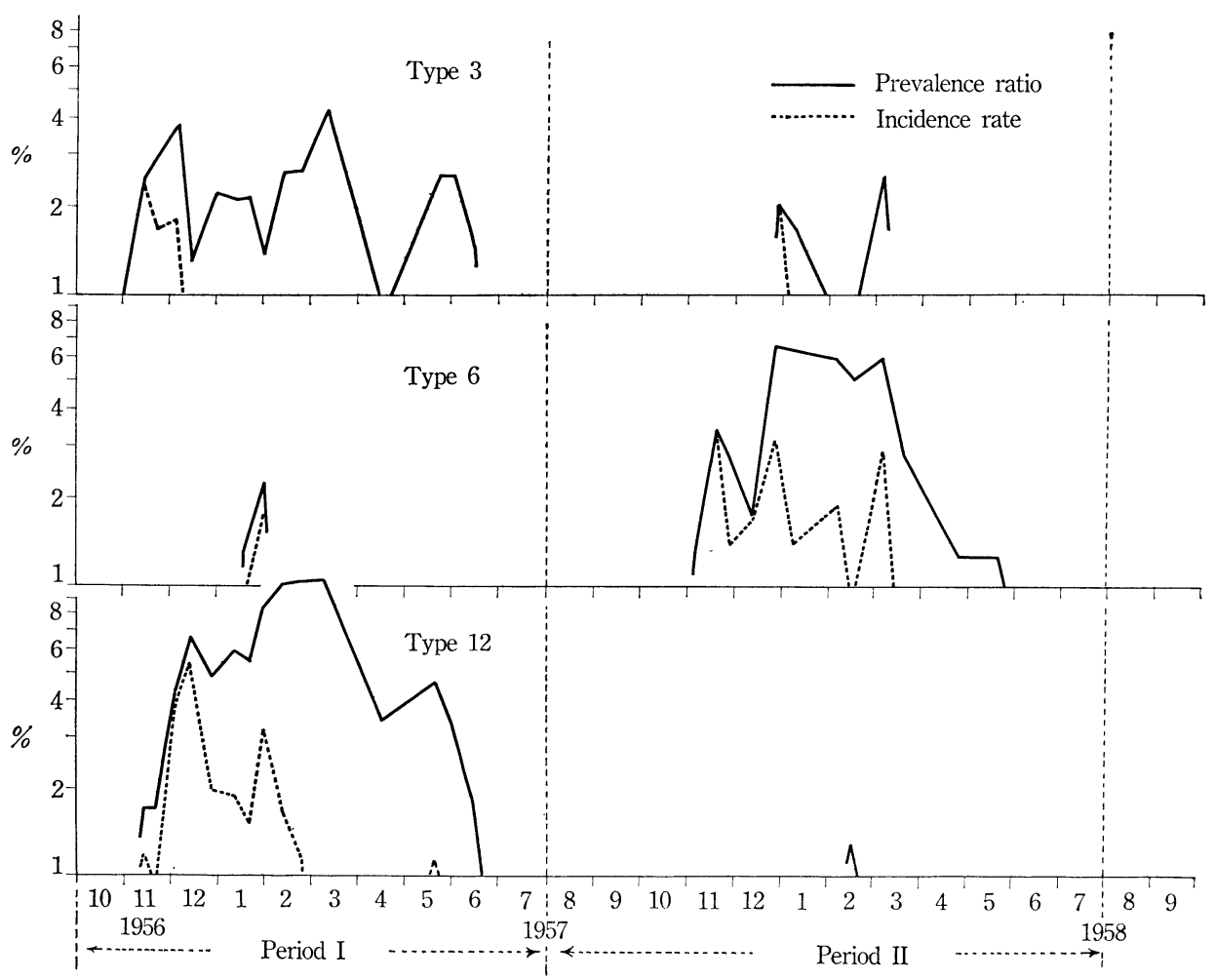

Fig. 2. Seasonal variation in the prevalence ratio and incidence rate of each prevalent type of Group A streptococcus.
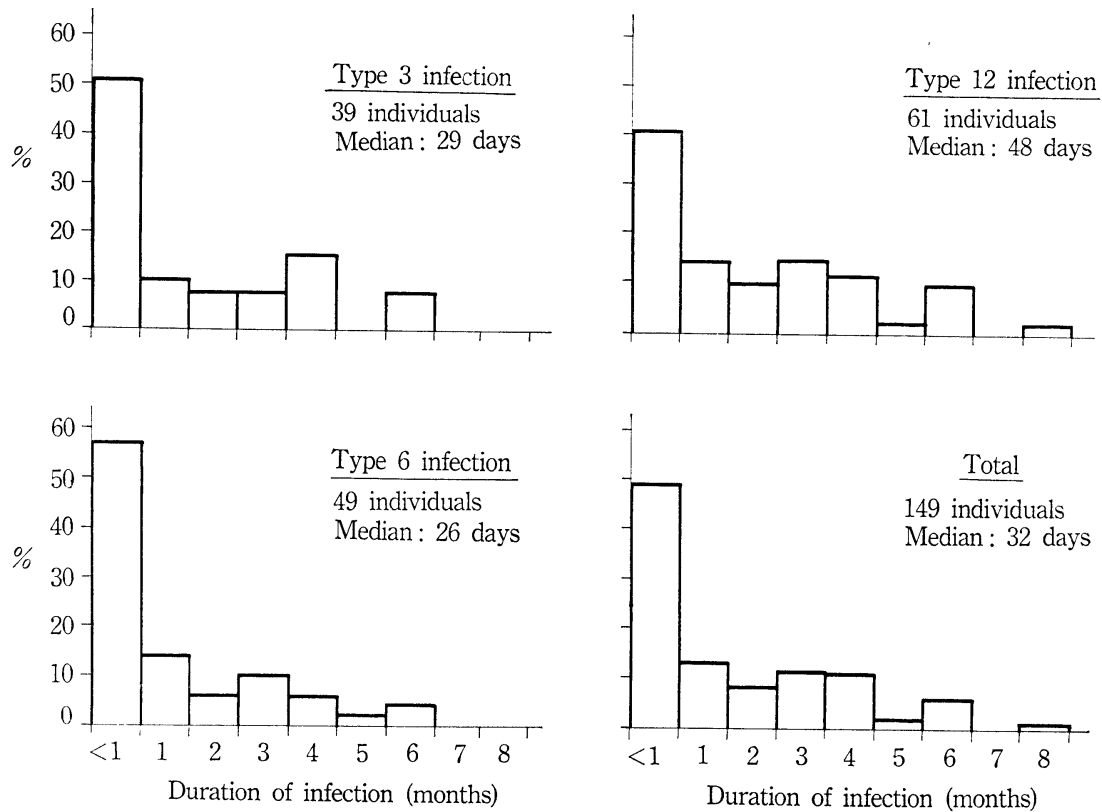

Fig. 3. Percentage distribution of duration of Group A streptococcal infection for each prevalent type. 
within each period was thus derived from the interval of time between the first and last appearance of the same type in the throat. In Fig. 3, the percentage distribution of the duration in months is illustrated for each prevalent type. The median duration was one month or so, and a few children were found to harbor the same type for more than 6 months. The serologic type of Group A streptococcus does not seem to determine the chronicity of the infection.

In the preceding chapters, the prevalence ratio of composite Group A streptococci or each prevalent type was shown to remain still at a high level for a few months, when the incidence rate was on the rapid decline after having passed the peak. This is entirely attributable to the long duration of the persistence of streptococci in the throat.

\section{Serological Observations}

\section{The Relationship of ASL Levels and the Occurrence of Subsequent Infections}

In May, 1957, blood samples were taken from 63 children who had been nagative for Group A streptococci from the begining of the survey and 6 children who newly entered the school in April, 1957 and since had yielded no streptococci. The frequency distribution of ASL titers in these children was found to be quite similar to that observed in lower grade children in a primary school in Tokyo (Kusama et al., 1962 a),

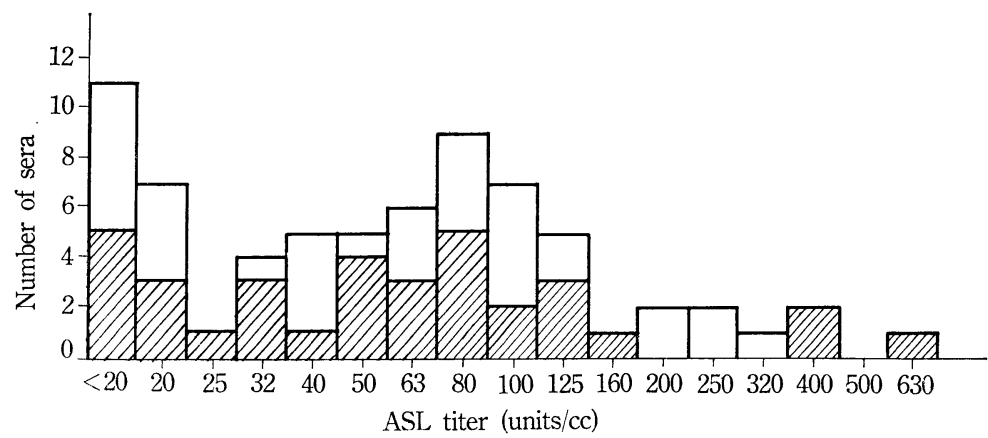

$\square$ Those who had no streptococcal infections during the period from May, 1957 to July, 1958.

ZIls Those who had streptococcal infections during the above period.

Fig. 4. Frequency distribution of ASL titers in 69 children in May, 1957 (including 6 newcomers) from whom streptococci had not been recovered before, and its relationshipe to streptococcal infections during the later study period.

consisting of the positive and negative groups, as shown in Fig. 4. Thirty-six of these children became infected mostly with Group A and sometimes with Group G streptococci during the later study period, and their positions in the ASL distribution in May, 1957 are marked with shaded areas in Fig. 4. Since they had been negative for streptococci during the preceding 6 months, their ASL levels in May, 1957 had already been fairly well stabilized, and further decline in the later period may be very slight. In other words, when they became infected their ASL titers were at about the same levels as in May, 1957. This assumption is well justified by the follow-up 
study of ASL titers in scarlet fever patients (Kusama et al., 1962c) and the observation of Rantz et al. (1948). Fig. 4 shows that ASL titers of these 36 children are distributed quite at random among a total of 63 children. It is certainly impossible to relate the occurrence of infections in 36 children to a particular level of ASL before infection, and the streptococcal infection may be considered to develop, regardless of the possession of ASL.

\section{The Harboring of Streptococci and Antibody Rise}

Blood samples were obtained again from 27 out of the above 36 children after the infection was established in them. Although the blood should be drawn 3-4 weeks after the onset of infection in order to see the maximum antibody rise, the circumstances

ASL titer before infection (May, 1957) (units/cc)

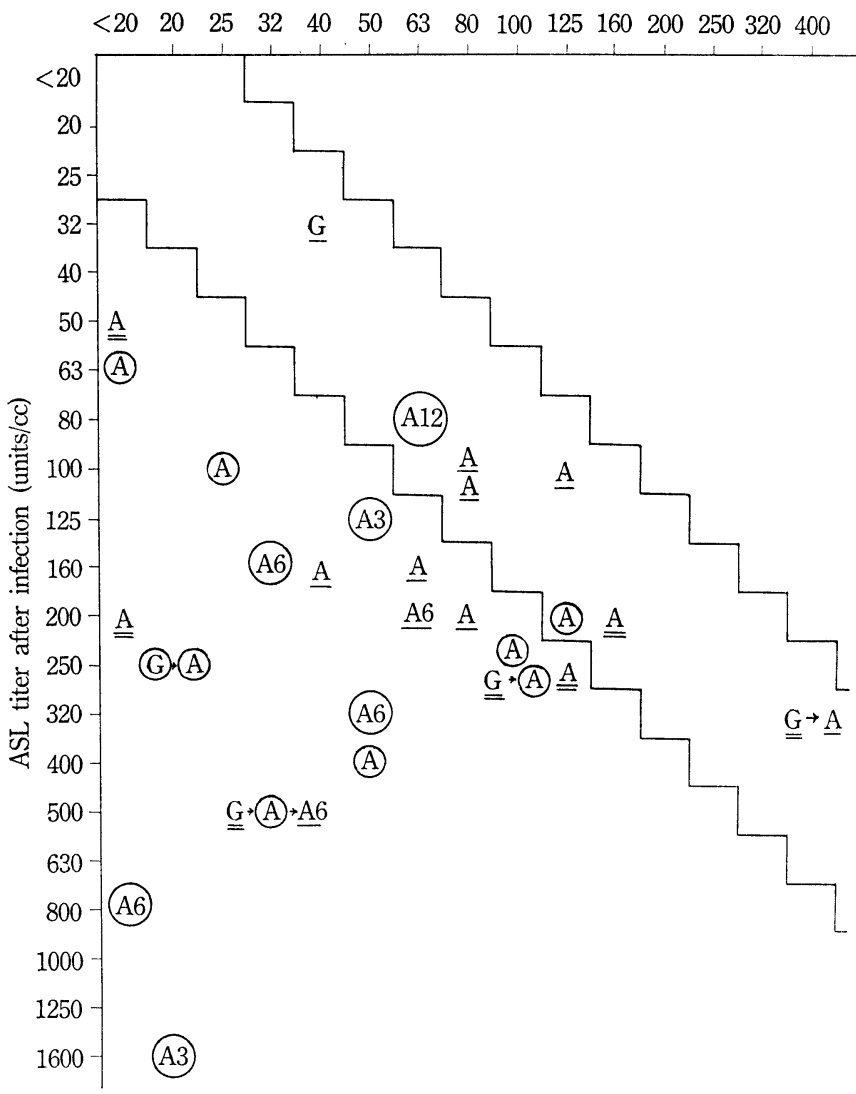

Infecting organisms are indicated at each point as follows :

A-Group A untypable ; A3-Group A type 3; A6-Group A type 6 ; A12-Group A type 12 ; G-Group G.

Interval between the date of recognized infection and that of the 2nd bleeding is indicated as follows :

-: 10 days to 2 weeks; $\bigcirc: 3$ weeks to 3 months ; $=: 4$ to 8 months.

Fig. 5. Relationship of ASL titers before (May, 1957) and after treptococcal infection. 
in the present field study prevented the adequate bleedings for various reasons, and they were bled at varying intervals after infection, as indicated in Fig. 5. Fig. 5 shows the relationship of ASL titers in May, 1957 and those after infection in 27 children, each individual being marked with the infecting organism and the time of bleeding. As discussed in the preceding chapter, the titers in May, 1957 may be considered to be much the same as those which might be at the time of infection (the initial titers). In those who were bled 10-14 days after infection, the antibody might not fully develop. In those who were bled 4-8 months after infection, the antibody titer might fall already, even if there was once an antibody rise. Those who were bled 3 weeks -3 months after infection, being marked with circles in the figure, can be most suitably subjected to the criticism for the antibody production. If an antibody rise to more than twice the initial titer is considered to be significant, the ASL titer was elevated as a whole in $19(70.3 \%)$ out of 27 children. Although the number of those who were adequately bled was unfortunately small, $12(85.8 \%)$ out of 14 showed a significant antibody rise. It is thus suggested that streptococci, especially Group A, are not simple saprophytic inhabitants in the upper respiratory tract, but the interaction of the organisms and the host really exists.

Since most of these children became infected during the period II and a few at the end of the period I, type 6 organisms were isolated most frequently from them among the typable Group A streptococci, and types 3 and 12 were encountered in a few cases. One child who was infected with type 3 showed an unusually high ASL response. It is in accordance with the results to be presented in the third report of the present series of investigations (Kusama et al., 1962b).

\section{DISCUSSION}

From September, 1955 to February, 1956, outbreaks of glomerulonephritis were reported in various parts of this country, and type 4 and 12 Group A streptococci were most frequently encountered among the typable organisms isolated from nephritic patients (Fukumi and Kusama, 1958). These incidences had induced much attention to the necessity of understanding the epidemiology of streptococcal infections, particularly in children, and of determining effective measures to control streptococcal infections. "The presents studies were performed without providing antibiotic treatment in order to see the natural dynamics of streptococcal prevalence in school populations.

The most characteristic findings are that the epidemic wave of group A streptococci recurred more or less in a similar fashion in each of two periods, but the serologic types which consitituted the epidemic wave were quite different in both periods. The incidence rate (the rate of newly infected to those who had not been infected before) of either total Group A organisms or each prevalent type reached the peak in the early phase of the epidemic wave (November-December). It is important that this phase just corresponds to the time at which streptococcal illness hav been found most frequently in this country. Although the epidemic wave reached the peak at the end of each calendar year in the present studies, Cornfeld et al. (1958) reported that the wave in school children reached the peak in late winter or early spring months. It may be due to differences in the community chosen and geographical conditions. A decline of certain types and a rise of others during a long period of observation of streptococcal epidemics have been reported by various workers (Schwentker et al., 1943, Coburn and Young, 1949; Wannamaker, 1954; Fukumi and Kusama, 1958). 
Wannamaker (1954) showed a variation of prevalent types from type 24 to type 14 during 1949 to 1952 . Our observation that types 12 and 3 predominating during the period I gave way to type 6 during the period II is another example of the change in prevalent types. While type 12 was predominating the period I, several nephritic patients occurred in the study group, and type 12 organisms were isolated from some of them.

About $60-70 \%$ of children became infected during the period I or II, and only $18 \%$ remained free from infection throughout both the periods, indicating a wide dissemination of the organisms in a school community. Our situation is similar to that reported by Quinn et al. (1957), but Cornfeld et al. (1958) reported that approximately one-half of the children had one or more positive cultures for beta homolytic streptococci in each of the two school years. Streitfeld et al. (1956) observed much lower rates than those by the above investigators. These differences naturally depend upon the community selected and a particular epidemic encountered at the time of investigations.

Immunological significance of ASL in human infections has been obscure, and ASL has been utilized only for the diagnostic purpose. In the present study, the streptococcal infection was suggested to occur, regardless of the possession of ASL, or ASL can not be considered to be responsible for the antibacterial immunity, being in contrast to the type-specific antibody. However, ASL might influence in some way the infection process or the development of clinical manifestations.

Rises in ASL titer were found in most of the children from whom blood specimens could be obtained before and after infection. Thus, they were considered to have undergone real infections, and not to be harboring saprophitic inhavitants. Meanwhile, Saslaw and Streitfeld (1956 and 1959) reported that several groups of streptococci including Group A were recovered frequently from throat cultures, without clinical signs or serological evidence of infection. Although detailed symptomatologic studies could not unfortunately be performed in the present studies, we assume that the reaction of the host cells is really taking place in the majority of those who are harboring Group A streptococci, eventually resulting in the antibody production.

\section{SUMMARY}

An epidemiological study of streptococcal infections in about 250 primary school children had been conducted from October, 1956 to September, 1958 by bacteriological and serological examinations, and the following results were obtained:

1. Seasonal variations in the occurrence of Group A streptococci were more or less similar in the period I (October, 1956-July, 1957) and period II (August, 1957July, 1958); the prevalence ratio reached the maximum at the end of each calendar year, and was minimum in summer.

2. Among the Group A organisms isolated, types 12 and 3 were most prevalent in the period I, but they became almost negligible in the period II. On the other hand, type 6 was predominating during the period II, whereas it was isolated only from a few cases during the period I.

3. The incidence rate (the rate of newly infected to those who had not been infected before) of either Group $\mathrm{A}$ or each prevelent type reached the peak in the early phase of epidemic.

4. Median duration of harboring the same type of streptococcus was about 1 
month, but a few children barbored the same type for more than 6 months.

5. The streptococcal infection was suggested to develop, regardless of the possession of ASL, and ASL was not considered to be responsible for the antibacterial immunity.

6. Rises in ASL titer were shown in most of children from whom blood specimens could be obtained before and after infection.

\section{REFERENCES}

Coburn, A. F. \& Young, D. C. (1949): The epidemiology of hemolytic streptococcus. Williams \& Wilkins Co., Baltimore.

Cornfeld, D., Werner, G., Weaver, R., Bellows, M. T. \& Hubbard, J. P. (1958) : Streptococcal infection in a school population: Preliminary report. Ann. Int. Med., 49, 1305-1319.

Fukumi, H. \& Kusama, H. (1958) : Serologic types of recently prevalent Group A streptococci and their relation to clinical manifestations. J. Jap. Ass. Infect. Dis., 31, 626-627 (text in Japanese).

KusAmA, H. (1958) : Studies on streptolysin O and antistreptolysin O. III. A practical method for the antistreptolysin O titration of human sera. Jap. J. M. Sc. \& Biol., 11, 375-382.

Kusama, H., Ohashi, M., Kobayashi, S., Fukumi, H., Habu, T., Sonoguchi, T. \& SHIMIZU, T. (1962a): Immunological significance of antistreptolysin O (ASL) in streptococcal infections. I. Sero-epidemiollogical studies in various age groups. Jap. J. M. Sc. \& Biol., 15, 175-187.

Kusama, H., Ohashi, M., Kobayashi, S., Fukumi, H., Habu, T., Yanagishita, T., Ogawa, J., Abe, M., Iimura, T., Hiraishi, K. \& Ueda, K. (1962b) : Immunological significance of antistreptolysin O (ASL) in streptococcal infections. III. The antibody response in scarlet fever patients. Jap. J. M. Sc. \& Biol., 15, 199-209.

Kusama, H., Ohashi, M., Kobayashi, S., Fukumi, H., Habu, T., Yanagishita, T., Ogawa, J., Abe, M., Iimura, T., Hiraishi, K. \& Ueda, K. (1962c): Immunological significance of antistreptolysin O (ASL) in streptococcal infections. IV. The antibody decline in scarlet fever convalescents. Jap. J. M. Sc. \& Biol., 15, 211-219.

Quinn, R. W., Denny, F. W. \& Riley, H. D. (1957) : Natural occurrence of hemolytic streptococci in normal school children. Am. J. Pub. Health, 47, 995-1008.

Rantz, L. A., Randall, E. \& Rantz, H. H. (1948) : Antistreptolysin "O": A study of this antibody in health and in hemolytic streptococcal respiratory disease in man. Am. J. Med., 5, 3-23.

SASLAW, M. S. \& STReitfeld, M. M. (1956) : Group A beta hemolytic streptococci in relation to rheumatic fever: Study of school children in Miami, Fla. Am. J. Dis. Child., 92, $550-557$.

SAsLAW, M. S. \& STREITfELD, M. M. (1959): Recovery of beta hemolytic streptococci from throats of mother and child: Relationship to respiratory illness. J. Infect. Dis., 104, 233-237.

Schwentker, F. F., JANney, J. H. \& Gordon, J. E. (1943): The epidemiology of scarlet fever. Am. J. Hyg., 38, 27-98.

Streitfeld, M. M., SASlaW, H. S. \& Doff, S. D. (1956) : Group A betahemolytic streptococcus and rheumatic fever in Miami, Florida. Pub. Health Rep., 71, 745-755.

SwifT, H. F., Wilson, A. T. \& LANCEFIELD, R. C. (1943): Typing Group A streptococci by $\mathrm{M}$ precipitin reactions in capillary pipettes. J. Exper. Med., 78, 127-133.

WANNAMAKER, L. W. (1954): The epidemiology of streptococcal infections. Streptococcal infections (edited by McCarty, M.), pp. 157-175, Columb a Univ. Press., New York. 